\title{
Enhanced Sunlight Photocatalytic Activity and Biosafety of Marine-Driven Synthesized Cerium Oxide Nanoparticles: A Future prospect
}

\section{Somayeh Safat}

Khorramshahr University of Marine Science and Technology

Foad Buazar ( $\nabla$ fb@kmsu.ac.ir)

Khorramshahr University of Marine Science and Technology

Soheila Matroodi

Khorramshahr University of Marine Science and Technology

Salim Albukhaty

University of Misan

\section{Research Article}

Keywords: Photocatalytic Activity, Cerium Oxide Nanoparticle, marine oyster extract

Posted Date: April 20th, 2021

DOI: https://doi.org/10.21203/rs.3.rs-422203/v1

License: (a) (i) This work is licensed under a Creative Commons Attribution 4.0 International License.

Read Full License

Version of Record: A version of this preprint was published at Scientific Reports on July 19th, 2021. See the published version at https://doi.org/10.1038/s41598-021-94327-w. 


\title{
Enhanced Sunlight Photocatalytic Activity and Biosafety of Marine-Driven Synthesized Cerium Oxide Nanoparticles: A Future prospect
}

\author{
Somayeh Safat ${ }^{\mathrm{a}}$, Foad Buazar ${ }^{\mathrm{a}}$, Soheila Matroodi ${ }^{\mathrm{b}}$, Salim Albukhatyc \\ ${ }^{a}$ Department of Marine Chemistry, Khorramshahr University of Marine Science and Technology, P.O. Box 669, \\ Khorramshahr, Iran \\ ${ }^{b}$ Department of Marine Biology, Khorramshahr University of Marine Science and Technology, P.O. Box 669, \\ Khorramshahr, Iran \\ ${ }^{c}$ Department of Chemistry, University of Misan, P.O. Box 62001, Maysan, Iraq \\ *Corresponding author, Tel: +98-916115084,Email: fb@kmsu.ac.ir
}

\begin{abstract}
This contribution presents the biosynthesis, physiochemical properties, and biological activity of biogenic $\mathrm{CeO}_{2} \mathrm{NPs}$ using, for the first time, marine oyster extract as an effective and rich source of bioreducing and capping/stabilizing agents in a one-pot recipe. $\mathrm{CeO}_{2} \mathrm{NPs}$ formation was initially confirmed through the color change from light green to pale yellow and subsequently, their corresponding absorption peak was spectroscopically observed at $310 \mathrm{~nm}$ with an optical band-gap of $4.67 \mathrm{eV}$ using the DR-UV technique. Further, XRD and Raman analyses indicated that nanoceria possessed face-centered cubic arrangements without any impurities, having an average crystallite size of $10 \mathrm{~nm}$. TEM and histogram results revealed that biogenic $\mathrm{CeO}_{2} \mathrm{NPs}$ was approximately spherical in shape with a median particle size of $15 \pm 1 \mathrm{~nm}$. The presence of various bioorganic substances on the surface of nanoparticles was deduced by FTIR and TGA results. It is found that marine-based nanoceria shows no cytotoxic effect on the cell, thus indicating their enhanced biocompatibility and biosafety to living organisms. In contrast, nanoceria demonstrated as an effective bactericidal agent toward pathogens. Visible light-activated $\mathrm{CeO}_{2}$ nanocatalyst revealed rapid photodegradation of methylene blue. Owing to simplicity, cost-effectiveness, and environmentally friendly nature, this novel marine biosynthetic route paves the way for prospective applications of nanoparticles in various areas of bioscience.
\end{abstract}




\section{Introduction}

In the last few years, biogenic nanoparticles have gained surging popularity in all fields particularly in medicine and bioscience mainly owing to their safety, biocompatibility, and biological properties ${ }^{1}$. The notion "biogenic" refers to a variety of biosynthetic pathways based on flora and fauna extracts. These natural resources include sea cucumber ${ }^{2}$, algae, plants, bacteria, yeast and fungi microorganisms among others ${ }^{3}$. Due to their intrinsic capabilities, green methodologies facilitate the reduction of dissolved metal ions to zero valence state and the production of pertaining nanoparticles. More specifically, marine resources hold the most promising area for the development of a new generation of the biological nanoparticle. It is envisaged that water cover $71 \%$ of the Earth's surface and $96.5 \%$ of all the Earth's water is associated with the oceans ${ }^{4}$, hence, the teeming world of naturally occurring microorganisms with complexity and diversity in the marine ecosystem could consider as an essential and readily available factory for manufacturing beneficial and economical nanoscale materials for numerous applications. The thriving ocean environment is a rich source of bioactive compounds that increasingly have innovative contributions in wide pertinent of all viable areas such as biomedicine, biotechnology, food, and cosmetic product developments. Despite global growing intuitive concern on the substantial environmental detrimental facet, an appreciable number of researches yet focus on chemical and physical methods. Therefore, a comparatively inconsiderable proportion of the literature reports has allocated to the utilization of sustainable marine sources specifically algae organisms for the green synthesis of nanoparticles ${ }^{5}$.

The edible oysters (Saccostrea cucullata) as a seafood are marine invertebrates belonging to brackish bivalve molluscs. They are dweller of intertidal zones and rich in a myriad of bioactive substances including carbohydrates, polyphenols, peptides, vitamins (vitamins A and B12), 
minerals (calcium and zinc), and proteins ${ }^{6}$. Traditionally, oyster's consumption whether food or medicine are prevailed in Asian countries especially those living in coastal regions ${ }^{7}$. It is estimated that around two billion oysters are consumed annually since they are nutritionally balanced source of food and impart great health benefits. As a valuable ocean resource of the blue economy, the bulkier rock oyster and Pacific oyster species commercially hold predominant contribution in therapeutic, food, cosmetics products, and hence, they are cultivated all year round.

In recent years, cerium oxide nanoparticles $\left(\mathrm{CeO}_{2} \mathrm{NPs}\right.$, nanoceria) have been received momentous interest owing to their inimitable physiochemical properties, biocompatibility, and bioactivities ${ }^{8,9}$. They were broadly exploited in various fields such as therapeutics agents in acute kidney injury ${ }^{10}$, catalysis, drug delivery careers, and environmental pollution scavenger ${ }^{11}$. It is found that effective oxidative stress, free-radical scavengers' role, and enzyme-mimetic catalytic performance of nanoceria mostly due to variation between the $\mathrm{Ce}^{4+}$ and $\mathrm{Ce}^{3+}$ cations proportion which on account of oxygen deficiencies in lattice arrangement of the nanoceria crystal structure. The presence of oxygen vacancy sites, remarkably promote reduction-oxidation reactions of $\mathrm{CeO}_{2}$ NPs in living cell regimes and thus, render them highly effective therapeutics candidate in diagnoses and treatment a number of microbial pathogens and other neurodegenerative disorders ${ }^{12}$. On the other hand, the promoted biological properties of nanoceria are remarkably affected by the synthesis routes which in turn induce miscellaneous particle size, shape, and size distribution. In this connection, a number of chemical and physical synthetic pathways has been addressed the production of nanoceria ${ }^{13}$.

In this study, we present a novel synthetic approach for the generation of $\mathrm{CeO}_{2} \mathrm{NPs}$ utilizing marine oyster extract as a facile, cost-effective, and eco-friendly platform of which ample phytochemicals play multiple roles in reduction, stabilization, and fine distribution of nanoceria 
through oxidation-reduction (redox) reactions (Fig. 1). The pertaining physicochemical characterization influencing the biological synthesis of marine-mediated $\mathrm{CeO}_{2} \mathrm{NPs}_{\text {are }}$ scrutinized and elucidated as well. The cytotoxicity and photocatalytic properties of green nanoceria have investigated against healthy cells and cationic biomedical dye.

\section{Result and discussion}
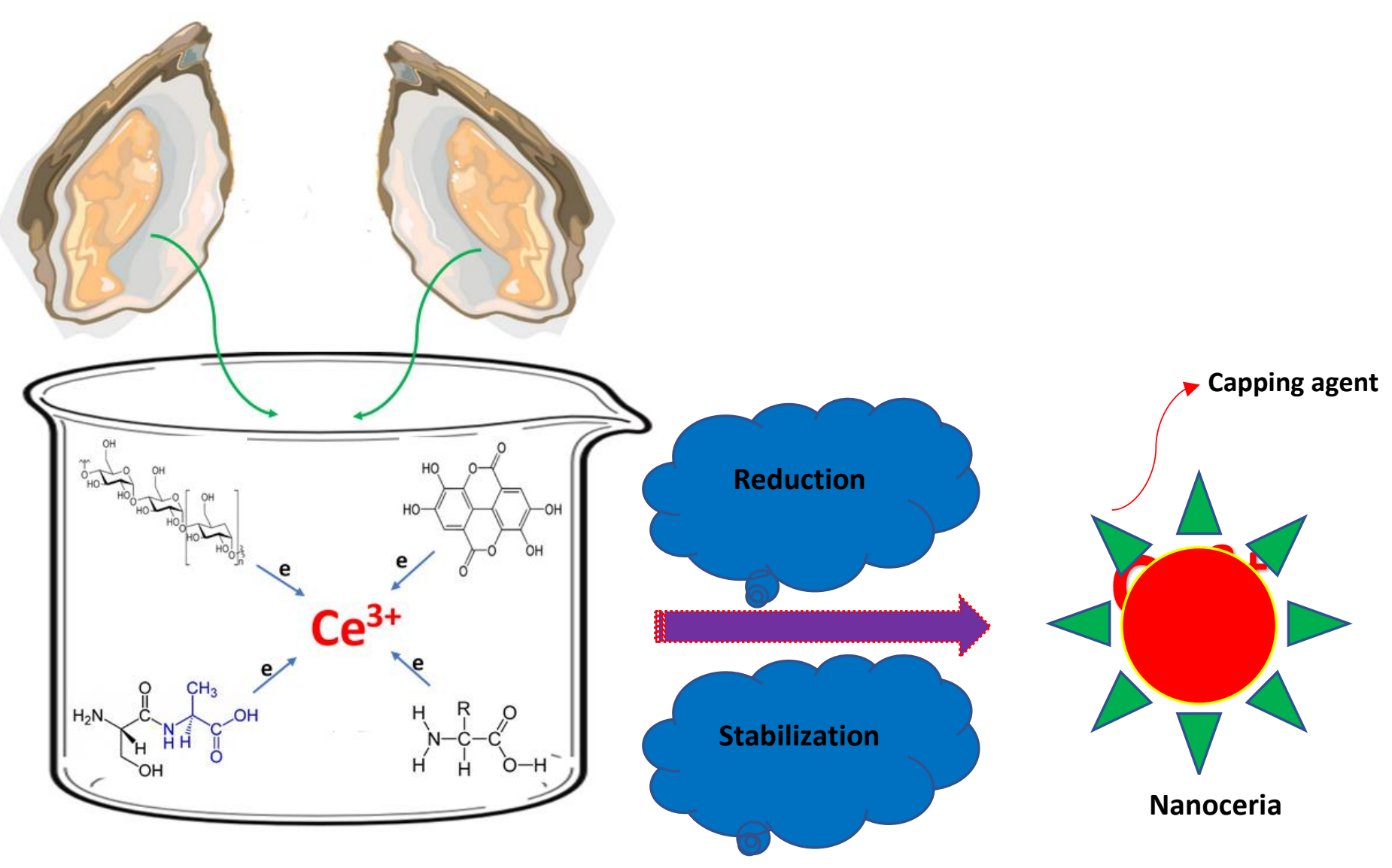

Figure1: Schematic representation of the biosynthetic pathway of nanoceria using marine oyster

\section{UV-vis analysis}


The primary visual observation of $\mathrm{CeO}_{2}$ NPs formation was discerned when the solution color changed from light-green to pale yellow slurry ${ }^{14}$. Further, the confirmation of optical absorption behavior of the bioproduced nanoceria powder was ascertained in the DR-UV spectroscopy showing a sharp absorbance peak at $310 \mathrm{~nm}$. (Figure $2 \mathrm{a}, \mathrm{b}$ ). The rate of a reaction attributed to bioreduction of cerium cations and production of nanoparticles was monitored using a fixed wavelength UV-vis spectrophotometer as a function of a variable time interval ( $5 \mathrm{~min}, 10 \mathrm{~min}, 20$ $\min , 40 \mathrm{~min}, 1 \mathrm{~h}, 2 \mathrm{~h}$ ). The results revealed that after $40 \mathrm{~min}$ the reaction reached the fullest and hence it was completed appearing no significant change beyond this time in peak position or intensity, as illustrated in figure 1b. In a similar study, Sarani and Miri demonstrated a comparable absorption peak at 317 which was assigned to the biosynthesized $\mathrm{CeO}_{2}$ NPs using the aqueous extract of Prosopis farcta ${ }^{15}$. Using the Tauc equation, $(\alpha h v)^{2}=(A)^{2}(h v-E g)^{2}$, the direct optical band-gap (Eg) of the biosynthesized $\mathrm{CO}_{2}$ NPs was estimated to be $4.67 \mathrm{eV}$ which is remarkably higher than the corresponding bulk cerium oxide value $(3.19 \mathrm{eV})$ (Fig. 3) ${ }^{16}$. 


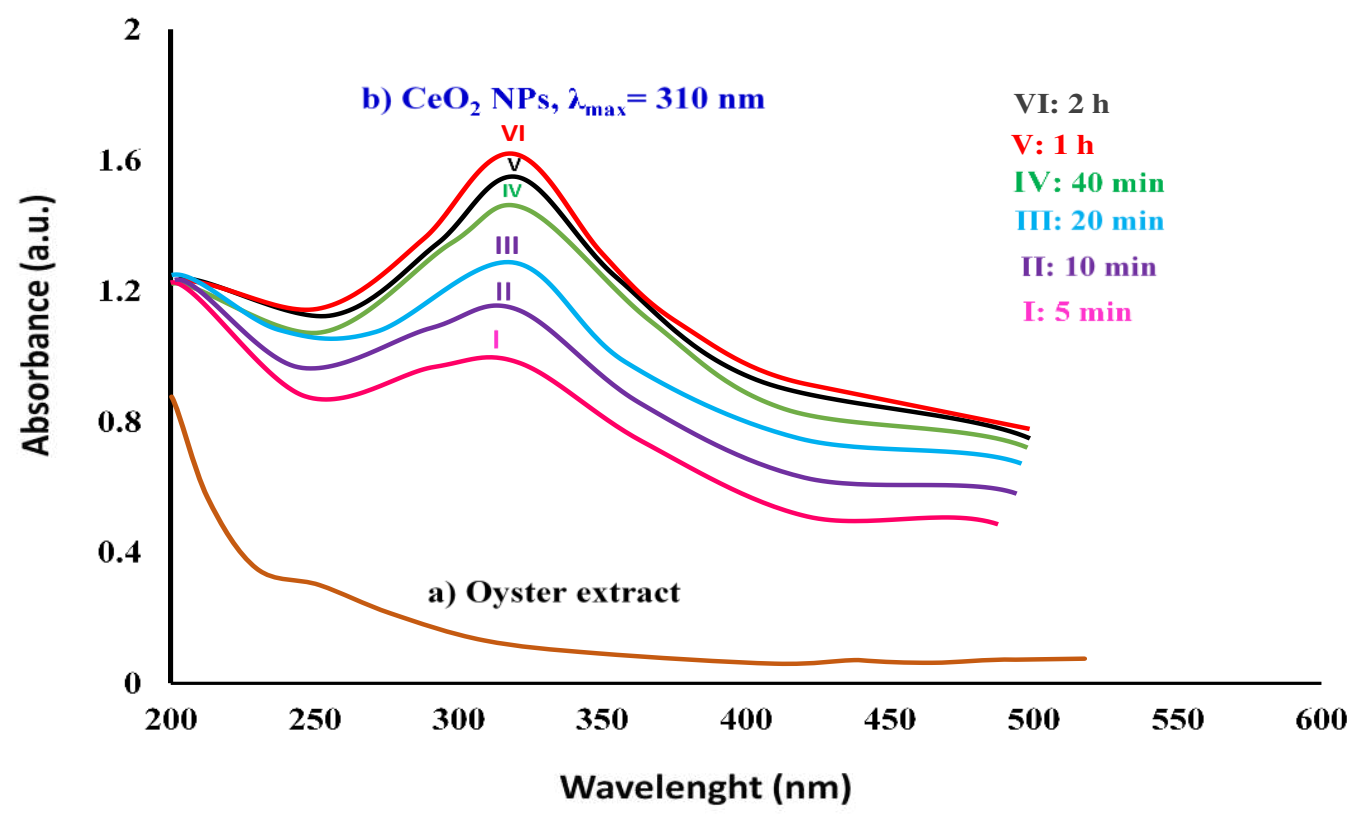

Figure 2: UV-vis spectra of (a) raw oyster extract and (b) bioprepared $\mathrm{CeO}_{2} \mathrm{NPs}_{\text {as }}$ function of time

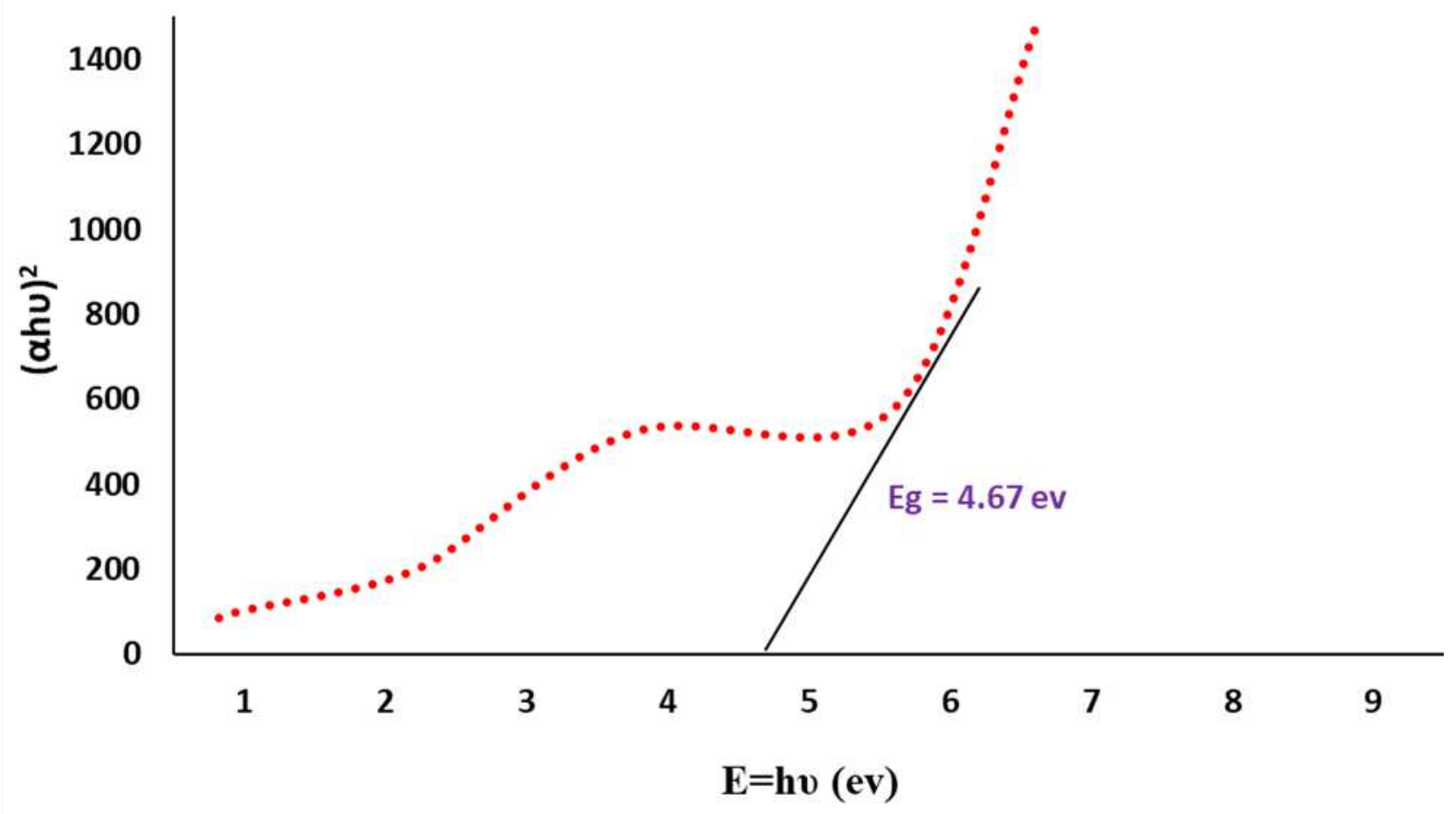

Fig. 3. Tauc plot of biosynthesized $\mathrm{CeO}_{2} \mathrm{NPs}$ using marine oyster extract 


\section{XRD characterization}

Figure 4 illustrates the XRD pattern of biofabricated $\mathrm{CeO}_{2} \mathrm{NPs}$. The presence of eight diffraction peaks corresponds to (111), (200), (220), (311), (222), (400), (331), and (420) crystallographic planes are precisely well matched to Joint Committee on Powder Diffraction Standards (JCPDS) (card no 96-900-9009). The obtained crystal lattice demonstrates that biogenic $\mathrm{CeO}_{2} \mathrm{NPs}$ possess a single-phase cubic fluorite structure where each cerium site is occupied by eight oxygen sites in a face-centered cubic fashion $\left(\mathrm{a}=\mathrm{b}=\mathrm{c}=5.14, \alpha=\beta=\gamma=90^{\circ}\right)$. In an akin research, Maqbool et al., reported that biosynthesized $\mathrm{CeO}_{2} \mathrm{NPs}$ by Olea europaea leaf extract shows a single face cubic center (fluorite structure) ${ }^{17}$. Moreover, no additional peaks were observed in the XRD pattern, indicating the purity of bioproduced nanoparticles. Using Debye-Scherrer equation, and from the most intensive broad Bragg peak at $28.54^{\circ}$, the approximate crystallite size of $\mathrm{CeO}_{2} \mathrm{NPs}$ was found to be $8.42 \mathrm{~nm}$.

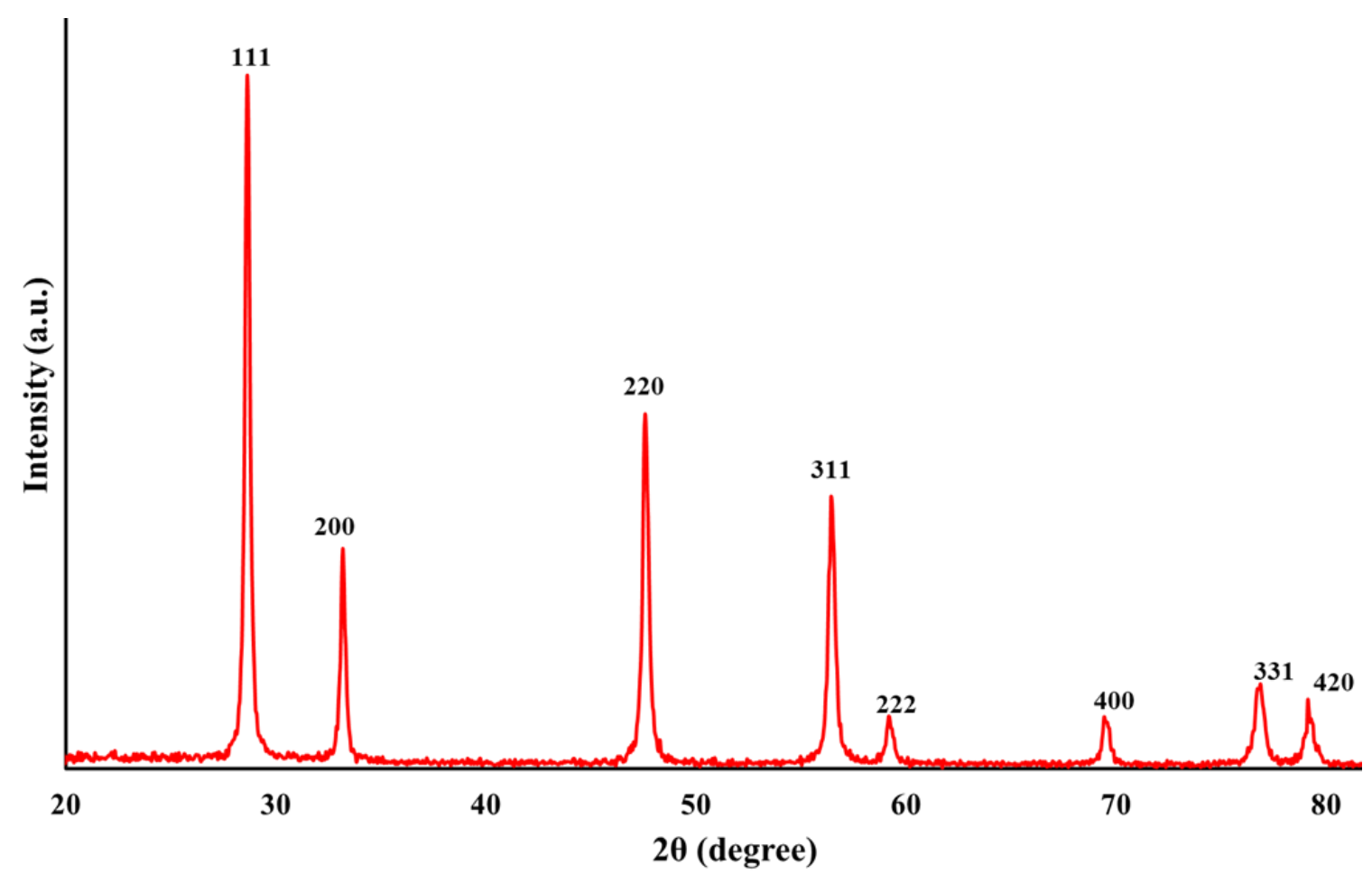

Figure 4: XRD pattern of the marine Oyster assisted biosynthesized $\mathrm{CeO}_{2} \mathrm{NPs}_{\text {. }}$ 
Correspondingly, the Raman spectrum of nanoceria depicted a noticeable peak at $456 \mathrm{~cm}^{-1}$ which is may attribute to the $\mathrm{F}_{2 \mathrm{~g}}$ Raman active mode, confirming cubic fluorite crystal structure of biogenic nanoceria, supporting the XRD results (Fig. 5) ${ }^{18}$.

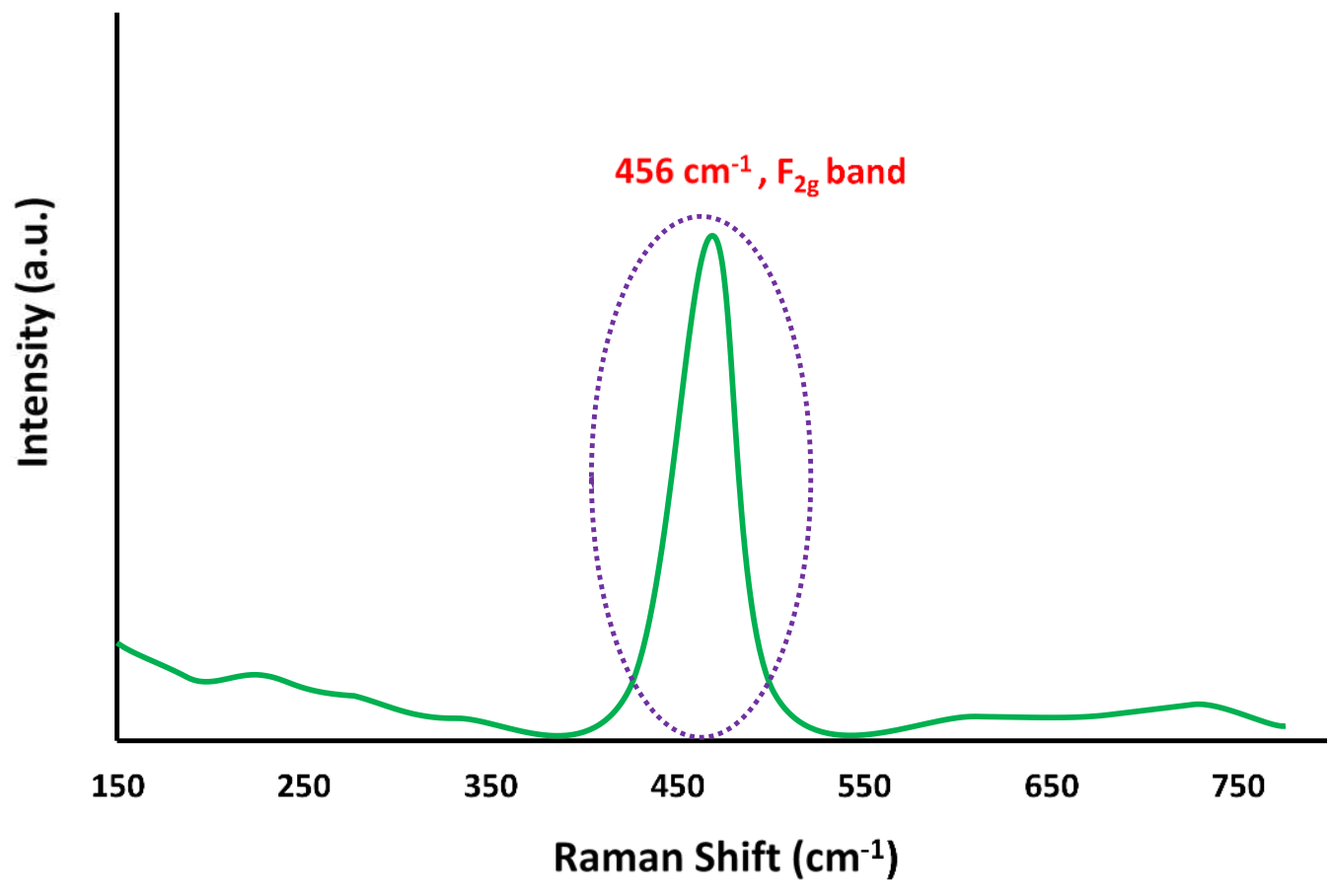

Figure 5: Raman spectrum of biofabricated $\mathrm{CeO}_{2} \mathrm{NPs}$ using marine oyster extract

\section{FTIR analysis}

The surface chemistry of the sample was scrutinized using the FTIR technique. The related spectrum of bioprepared $\mathrm{CeO}_{2}$ NPs was illustrated in Fig. 6. The presence of several bands in the spectrum shows a wide range of marine oyster-derived biomolecules on the surface of nanoparticles. The strong and broad absorption peak at $3450 \mathrm{~cm}^{-1}$ is assigned to the plethora of hydroxyl groups, $\mathrm{O}-\mathrm{H}$, and $\mathrm{N}-\mathrm{H}$ stretching due to water, carbohydrates, polyphenols, and probably proteins. The band at $2915 \mathrm{~cm}^{-1}$ is associated with aliphatic symmetric $\mathrm{C}-\mathrm{H}$ group stretching of carbohydrates. The characteristic vibration band of the carbonyl group $(\mathrm{C}=\mathrm{O})$ was 
observed at $1755 \mathrm{~cm}^{-1}$. The $\mathrm{C}-\mathrm{N}$ stretch appears in the region $1400 \mathrm{~cm}^{-1}$. The weak $\mathrm{C}-\mathrm{H}$ bending band of alkane compounds was appeared at $1365 \mathrm{~cm}^{-1}$. The vibration bands of ether functional group $(\mathrm{C}-\mathrm{O}-\mathrm{C})$ linkage related to polysaccharides is centered at $1058 \mathrm{~cm}^{-1}$. The a quite strong stretching peak around $1000 \mathrm{~cm}^{-1}$ is related to $\mathrm{C}-\mathrm{OH}$ of primary and secondary alcohols ${ }^{19}$. The advent frequency bands at $745 \mathrm{~cm}^{-1}$ and $540 \mathrm{~cm}^{-1}$ are attributed to $\mathrm{Ce}-\mathrm{O}$ bonds stretching of bioproduced $\mathrm{CeO}_{2} \mathrm{NPs}$. The presence of copious phytochemicals in green reaction medium act a dual role as reducing and stabilizer agents of respective nanoceria ${ }^{17}$. As to the reduction process, this occurred through an electron transfer via redox reaction between electron-rich biomolecules (the reducing agent) as an electron donor and cerium cations as an electron acceptor (the oxidizing agent). Finally, the produced metallic cerium atoms upon exposure to the air oxygen would facilely produce $\mathrm{CeO}_{2}$ nanoparticles as reported in similar researches indicating biofabrication of nanoparticles via various biological derivatives ${ }^{12,20}$.

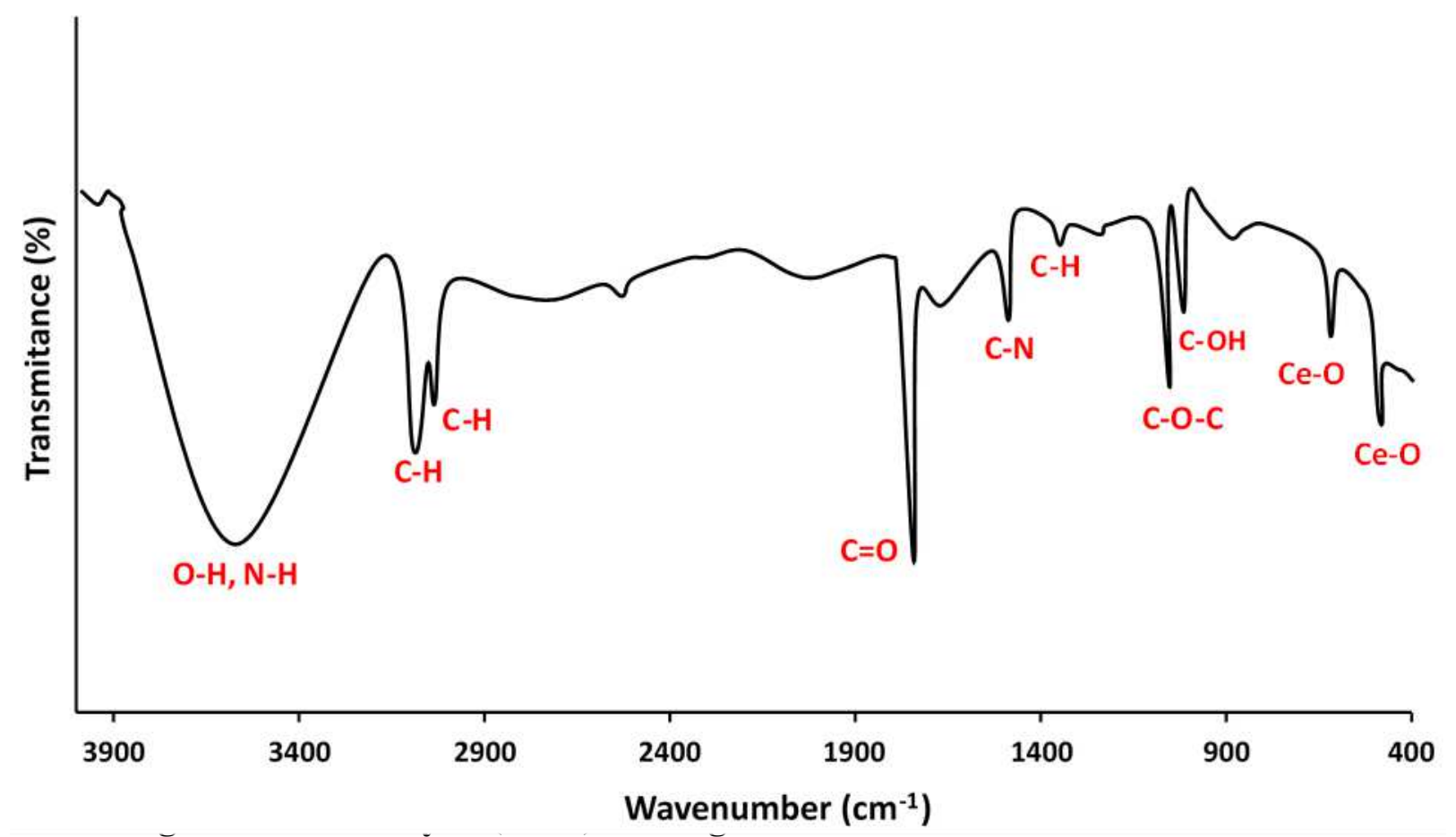

Figure 6: FTIR spectrum of the marine oyster assisted biosynthesized $\mathrm{CeO}_{2} \mathrm{NPs}_{\text {. }}$ 
The TGA curve of the biomolecules-capped nanoceria biofabricated using marine oyster extract in the temperature range of $100-700{ }^{\circ} \mathrm{C}$ is depicted in Fig. 7. TGA reveals two different weight loss percentages of the nanoceria specimen. The first degradation with $10 \%$ weight loss was detected in the temperature range of $50-200{ }^{\circ} \mathrm{C}$ likely owing to the evaporation of physicallyadsorbed water molecules on the surface of $\mathrm{CeO}_{2}$ NPs. The second major mass change was appeared at temperature variation between $225-400{ }^{\circ} \mathrm{C}$ with $45 \%$ of the overall weight probably on account of desorption of marine-derived organic compounds in the nanoceria. Eventually, no reduction in the TGA plot was remarked, upon the further rise in the temperature indicating constant size maintenance of the sample. These results reveal the presence of marine-derived organic moieties on the surface of $\mathrm{CeO}_{2} \mathrm{NPs}$ and hence confirm FTIR spectra findings.

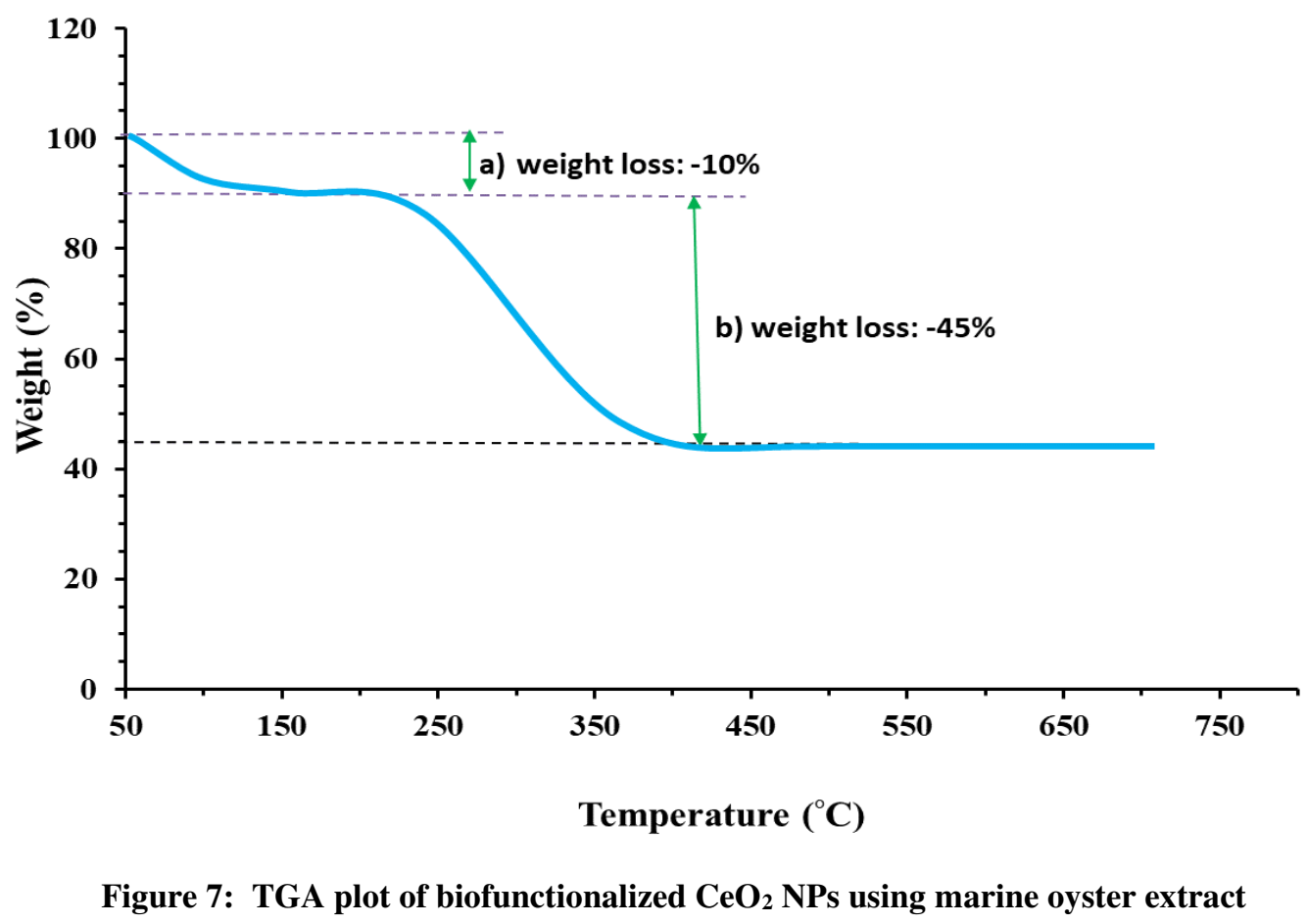

TEM characterization 
TEM technique is powerful tool to determine the size and shape of designed nanoparticles. The TEM image of biological nanoceria using marine oyster extract is depicted in Fig. 8. It is found that biosynthesized $\mathrm{CeO}_{2} \mathrm{NPs}$ are well dispersed and contained particles relatively spherical in shape. The distribution particle size histogram obtained from the TEM micrograph analysis via ImageJ software exhibits an insignificant variation in particle size with a median diameter of $30 \pm 1$ nm. Likewise, plant extract-mediated biosynthesized nanoceria indicated spherically shaped geometry with a size of 10-70 nm mainly resulted from functional phenolic and flavonoids derived from $O$. majorana $L$. leaf extract ${ }^{20}$.
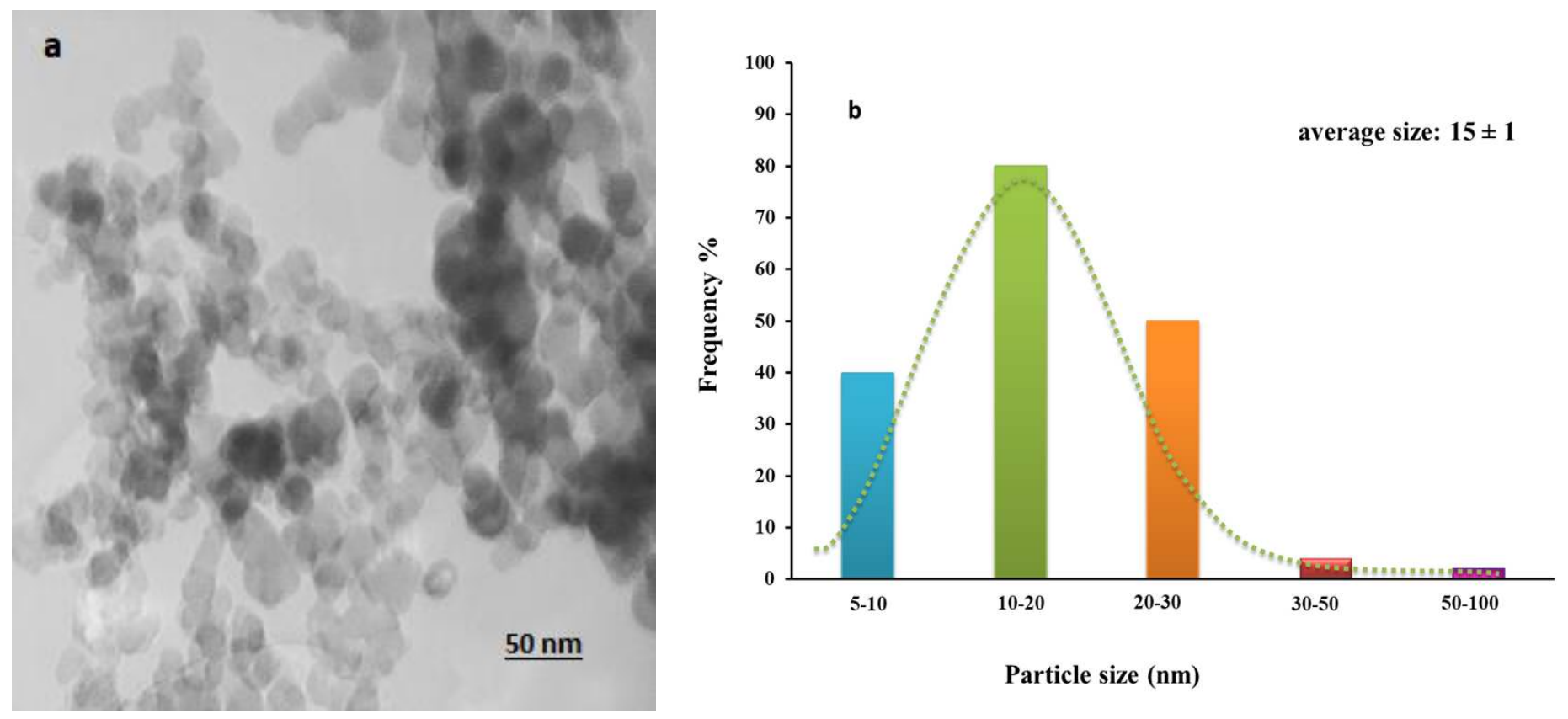

Figure 8: (a) TEM image and (b) particle size distribution histogram plot of the marine oyster assisted biosynthesized $\mathrm{CeO}_{2}$ NPs.

\section{Cytotoxic assay of green $\mathrm{CeO}_{2} \mathrm{NPs}$}


To assess the potential cytotoxicity, we explored MTT assays to test the viability of L929 fibroblast cells subjected to concentrations of control (nanoceria-free) and $\mathrm{CeO}_{2} \mathrm{NPs}$ at 3.75, 7.5, 15, 30, and $60 \mu \mathrm{g} / \mathrm{mL}$ and varying exposure time $(24,48,72 \mathrm{~h})$. As can be clearly seen in Fig. 9, the marinemediated nanoceria are approximately nontoxic toward normal cell line indicating their biocompatibility and biosafety. Regardless of the nanoceria concentrations, the best result was observed at $72 \mathrm{~h}$. In regard to exposure time, while the lowest percentage of cell viability was noticed at $48 \mathrm{~h}$ for $7.5(92.09 \%)$ and $15 \mu \mathrm{g} / \mathrm{mL}$ (92.32\%), respectively. However, the efficiency of marine-assisted $\mathrm{CeO}_{2}$ NPs are mainly concentration and time dependent and one is not able to address the constant trend signifying cytotoxicity manner of nanoparticles. The akin phenomena has been reported for green silver nanoparticles toward L929 cell line confirming our findings ${ }^{21}$. In a similar study also when rat cardiomyocytes (H9C2) and human brain fibroblast cells (T98G) were exposed to a $5 \mathrm{mg} / \mathrm{mL}$ dose of $30 \mathrm{~nm} \mathrm{CeO}_{2}$, no major cytotoxicity was observed ${ }^{22}$. Being nontoxic nature of bio-prepared nanoceria could be highly likely attributed to the presence of substantial marine-derive biomolecules covered the surface of nanoparticle boosting their bioactivity and safety toward healthy cells as conformed with several literature reports ${ }^{13,23}$. 


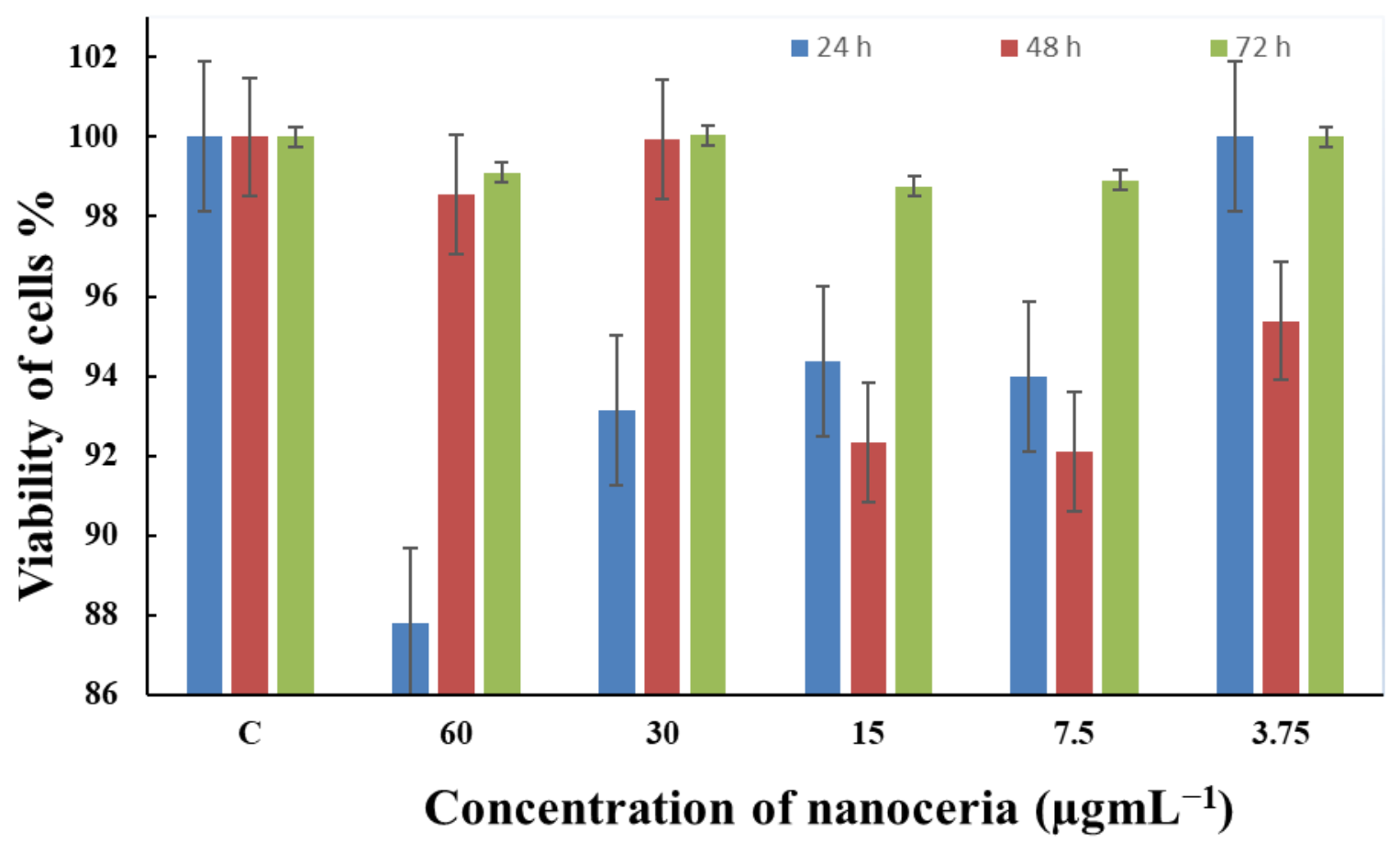

Figure 9: Cytotoxicity and biosafety of marine-mediated nanoceria $\left(\mathrm{CeO}_{2} \mathrm{NPs}\right)$ against healthy $\mathrm{L929}$ fibroblast cells

Photocatalytic activity of $\mathrm{CeO}_{2} \mathrm{NPs}$ 
The catalytic efficiency of the biogenic $\mathrm{CeO}_{2} \mathrm{NPs}$ was studied toward degradation of the organic methylthioninium chloride which is also known as Methylene Blue (MB). This heterocyclic aromatic compound is commonly utilized as day indicator in biochemistry and due to its redox properties has several medical applications including the treatment of methemoglobinemia, smooth muscle relaxation, NIR fluorescent dye, and surgical procedure. Despite widely using MB as human therapeutic agent, its detrimental environmental impact has raised serious concerns ${ }^{24}$. The photodegradation was carried out in daylight using sunlight as a natural activator. It is found that by loading an appropriate dose $(150 \mathrm{mg} / \mathrm{L})$ of biological $\mathrm{CeO}_{2} \mathrm{NPs}$, the intensity of UV-vis absorption peak of MB solution (150 ppm) at $633 \mathrm{~nm}$ was steadily disappeared within 60 min, thus demonstrating the rapid photocatalytic degradation of methylthioninium chloride contaminant from solution (Figure 10a). It can be noted that the relatively broad optical band gap of energy acquired for green nanoceria $(4.67 \mathrm{eV})$ easily triggered by visible sunlight, and hence, production copious superoxide radicals during the action has piercing effect on accelerated deterioration of $\mathrm{MB}^{25}$ (Figure 10b). Meanwhile, the reusability of $\mathrm{CeO}_{2} \mathrm{NPs}$ photocatalyst toward MB degradation was also explored. After 5 consecutive cycles, no significant change was observed in the catalytic activity of nanoceria in $\mathrm{MB}$ removal rate\%, indicating fairly high recyclability of biogenic $\mathrm{CeO}_{2}$ NPs (Figure 10c). As per economic and environmental prospective, our findings show greater efficiency rather than chemically-produced ceria nanoparticles toward same pollutant under UV irradiation ${ }^{26}$. 

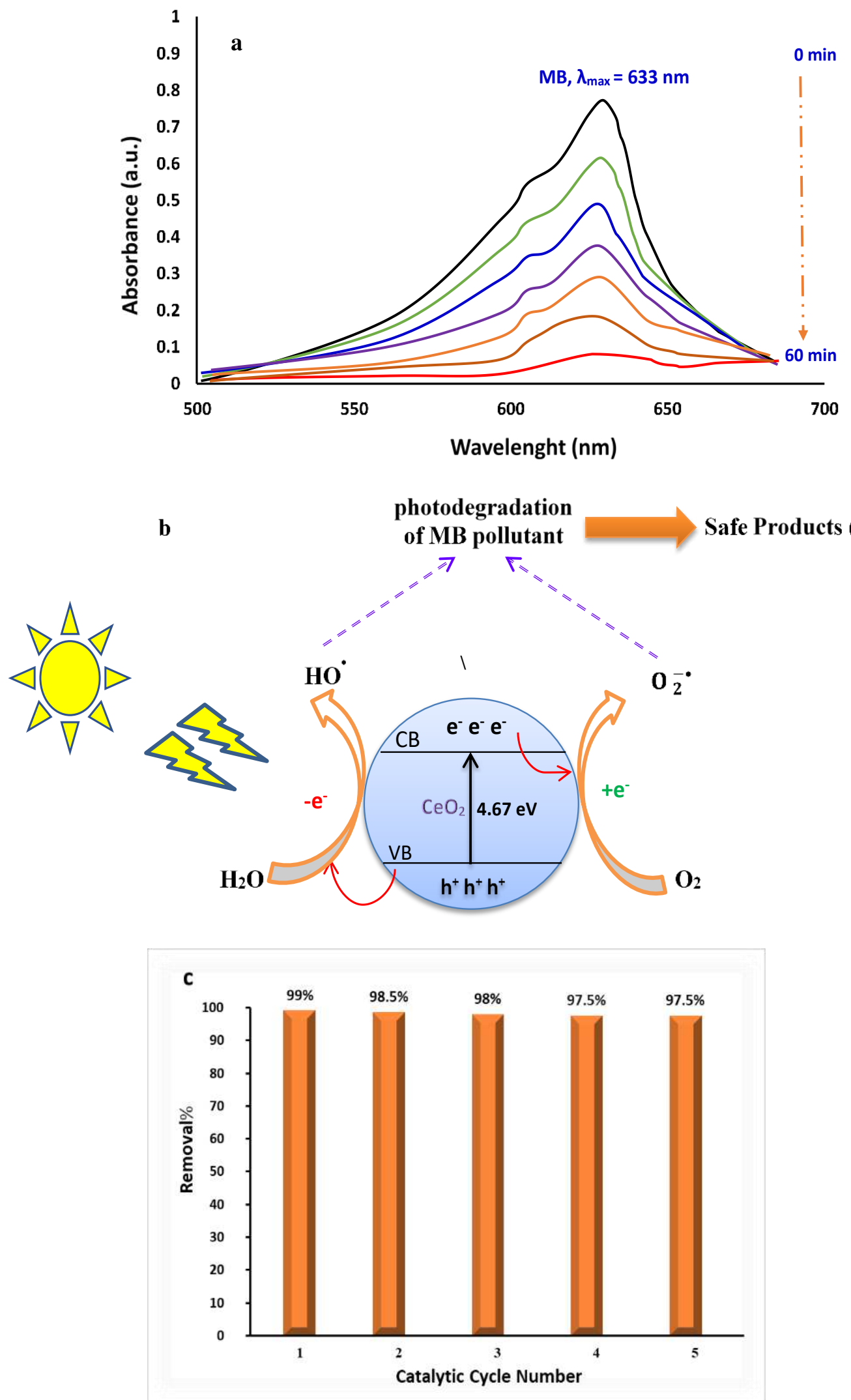

Figure 10: (a) Photocatalytic activity, (b) mechanism, and (c) recyclability of marine-mediated nanoceria against toward MB contaminant in aqueous solution 
In conclusion, we have developed a novel synthetic procedure for preparation of $\mathrm{CeO}_{2} \mathrm{NPs}$ using marine oyster extract. Based on FTIR and TGA analyses the oyster extracted biomolecules function as bioreductant and stabilizing agent in green synthesis process of nanoceria. In the presence of electron-donor marine-derived biomolecules the metallic cations in aqueous salt solution were reduced into corresponding nanoceria in a benign and nontoxic reaction condition. XRD and TEM results confirmed the cubic fluorite structure of biogenic $\mathrm{CeO}_{2} \mathrm{NPs}_{\text {sithout any }}$ impurities with a mean particle size of $15 \mathrm{~nm}$. During the photocatalytic action, the nanoceriagenerated superoxide radical are the dominant oxidants in MB elimination process. Further, the marine-mediated nanoceria show higher level of biological safety as no major cytotoxic effect has been noticed against cell line using MTT method. The designed approach presents great advantages including simplicity, biocompatibility, and high potency of large-scale production of nanomaterials for pharmacological

\section{Methods}

All chemical reagents were obtained from Sigma-Aldrich and used without further purifications.

Oyster extract preparation

The native raw Oysters (Ostreidae) species were collected from the rocky shores of Chabahar, Iran. Freshly shucked oyster muscles were completely washed using the tap and distilled water to remove any sediments and other foreign substances. the fleshes then were chopped into small bits, packed in aluminum foils, and freeze dried for $72 \mathrm{~h}$ at $-80{ }^{\circ} \mathrm{C}$. The dried specimens were then powdered by means of a mechanical mixer for $5 \mathrm{~min}$ and properly sieved to a desirable particle size through a stainless-steel sieve of the 9-mesh screen. Subsequently, ground sample material of $5 \mathrm{~g}$ was heated into a backer containing $200 \mathrm{~mL}$ of methanol at a temperature of $80{ }^{\circ} \mathrm{C}$ for 120 
mins. Finally, rotary evaporator extraction was performed at $40{ }^{\circ} \mathrm{C}$ to concentrate extract and evaporate the extra solvent.

\section{Biosynthesis of $\mathrm{CeO}_{2} \mathrm{NPs}$}

An aliquot of $0.5 \mathrm{~g}$ of Cerium (III) nitrate hexahydrate $\left[\mathrm{Ce}\left(\mathrm{NO}_{3}\right)_{3} \cdot 6 \mathrm{H}_{2} \mathrm{O}\right.$ ] was weighed and added to $100 \mathrm{ml}$ of methanolic oyster extract solution. Then the solution was mixed and heated in a water bath for $2 \mathrm{~h}$ under constant stirring at $150 \mathrm{rpm}$. In order to obtain homogeneous dispersion, the mixture further was subject to ultrasonic treatment performed at $150 \mathrm{~W}$ power and $35 \mathrm{kHz}$ frequency for $10 \mathrm{~min}$. Once the resultant solution cooled down to room temperature a pale-yellow solid precipitate was attained. The ensuing solid was separated from the supernatant using constant centrifugation at $15000 \mathrm{rpm}$ for $5 \mathrm{~min}$. The precipitate was then dried at $95^{\circ} \mathrm{C}$ overnight in an oven to remove additional impurities.

\section{Cytotoxicity experiment of biological nanoceria}

For the evaluation of the cytotoxic effect and biocompatibility of bioprepared $\mathrm{CeO}_{2}$ NPs, MTT (3Dimethylthiazo-2, 5-diphynyltetrazolium Bromide) assay was used on L929 cell line following instruction from the manufacturer and literature ${ }^{27}$. L929 is a normal fibroblast cell line from subcutaneous connective tissue of mouse of which their cultures were incubated at a density of $1 \times 105$ cells per well at $37^{\circ} \mathrm{C}$ in $5 \% \mathrm{CO}_{2} . \mathrm{CeO}_{2} \mathrm{NPs}$ were added in different concentrations, and after $24 \mathrm{~h}$, the cells were washed twice with phosphate buffer saline (PBS) before adding fresh $100 \mu \mathrm{L}$ of culture medium and $0.5 \mathrm{mg} / \mathrm{mL}$ of MTT reagent to each well. The control group served as the non-labeled cells. Subsequently, the labeled cells were incubated at $37^{\circ} \mathrm{C}$ in $5 \% \mathrm{CO}_{2}$ for 4 $\mathrm{h}$, the medium was kindly aspired and replaced by $100 \mu \mathrm{g} / \mathrm{mL}$ of fresh DMSO. Dissolved formazan product absorbance was measured at a wavelength of $570 \mathrm{~nm}$. The mean optical density (OD, 
absorbance) of four wells in the indicated groups was employed to measure the percentage of cell viability as below:

Percentage of cell viability $=\left(A_{\text {Sample }} / A_{\text {Control }}\right) \times 100$

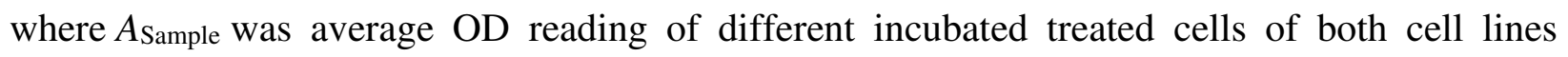
and $A_{\text {Control }}$ was average OD reading of the different incubated cells in complete culture media only. The cytotoxicity of the cells was then assessed from the average triplicate values and exhibited as mean \pm standard deviation (SD).

\section{Catalytic properties of biogenic nanoceria}

The photocatalytic activity of $\mathrm{CeO}_{2}$ NPs for degradation of organic methylene blue (MB) as biomedical day agent was explored in visible region under sunlight irradiation based on literature report ${ }^{8}$. In so doing, in a transparent approximately flat beaker, a $150 \mathrm{mg}$ of nanoceria is well dispersed in $150 \mathrm{ppm}$ of respective MB under optimized conditions. All the experiments of samples were inspected for a period of $60 \mathrm{~min}$. A $10 \mathrm{ml}$ sample was taken each $10 \mathrm{~min}$ interval and the photodegradation process was monitored using UV-vis spectrophotometer at the maximum absorption wavelength of MB $(633 \mathrm{~nm})$.

\section{Characterization of biomediated $\mathrm{CeO}_{2} \mathrm{NPs}$}

The biosynthesized $\mathrm{CeO}_{2}$ NPs were systematically studied using a litany of characterization techniques using UV/vis spectrophotometer (Shimadzu UV-2550, Japan), FTIR (Shimadzu 8400S, Japan), XRD (PANalytic X'Pert MPD, PANalytical, Almelo, Netherlands), FESEM (Zeiss Sigma 500 VP, Germany), and TEM (Zeiss-EM10C-100Kv, Germany). Raman (Takram P50C0R10, laser wavelength $=532 \mathrm{~nm}$ ), and thermogravimetric analysis (TGA, PerkinElmer, Pyris 1, USA). 


\section{Author contributions}

F. Buazar designed and supervised this study. The experiment plan and the cytotoxicity test were conducted by S. Albukhaty, S. Safat accomplished the synthesis of nanoparticles and related experiments plan. Data analyses and related results of biosafety further was investigated with aide of S. Matroodi. All authors contributed to the writing and editing of the paper.

\section{Competing interests}

The authors declare no competing interests.

\section{References}

1 Sharma, D., Kanchi, S. \& Bisetty, K. Biogenic synthesis of nanoparticles: A review. Arabian journal of chemistry 12, 3576-3600 (2019).

2 Sepahvand, M., Buazar, F. \& Sayahi, M. H. Novel marine-based gold nanocatalyst in solvent-free synthesis of polyhydroquinoline derivatives: Green and sustainable protocol. Applied Organometallic Chemistry 34, e6000 (2020).

3 Pal, G., Rai, P. \& Pandey, A. in Green synthesis, characterization and applications of nanoparticles 1-26 (Elsevier, 2019).

4 Armstrong, C., Steffen, P. \& Martinez, E. Earth/Space Science-WATER, WATER: Water Resources. (2020).

5 Manivasagan, P. \& Kim, S. K. Biosynthesis of nanoparticles using marine algae: A review. Marine algae extracts: processes, products, and applications, 295-304 (2015).

6 Lee, H.-J., Saravana, P. S., Cho, Y.-N., Haq, M. \& Chun, B.-S. Extraction of bioactive compounds from oyster (Crassostrea gigas) by pressurized hot water extraction. The Journal of Supercritical Fluids 141, 120-127 (2018).

$7 \quad$ Nell, J. A. The history of oyster farming in Australia. Marine Fisheries Review 63, 14-25 (2001).

8 Dhall, A. \& Self, W. Cerium oxide nanoparticles: a brief review of their synthesis methods and biomedical applications. Antioxidants 7, 97 (2018).

9 Mitchell, K. J., Abboud, K. A. \& Christou, G. Atomically-precise colloidal nanoparticles of cerium dioxide. Nature communications 8, 1-7 (2017).

10 Weng, Q. et al. Catalytic activity tunable ceria nanoparticles prevent chemotherapy-induced acute kidney injury without interference with chemotherapeutics. Nature communications 12, 1-14 (2021).

11 Dowding, J. M., Dosani, T., Kumar, A., Seal, S. \& Self, W. T. Cerium oxide nanoparticles scavenge nitric oxide radical ( NO). Chemical communications 48, 4896-4898 (2012).

12 Nadeem, M. et al. Green synthesis of cerium oxide nanoparticles (CeO2 NPs) and their antimicrobial applications: a review. International Journal of Nanomedicine 15, 5951 (2020).

13 Charbgoo, F., Ahmad, M. B. \& Darroudi, M. Cerium oxide nanoparticles: green synthesis and biological applications. International journal of nanomedicine 12, 1401 (2017). 
14 Rajeshkumar, S. \& Naik, P. Synthesis and biomedical applications of cerium oxide nanoparticlesa review. Biotechnology Reports 17, 1-5 (2018).

15 Miri, A. \& Sarani, M. Biosynthesis, characterization and cytotoxic activity of $\mathrm{CeO}_{2}$ nanoparticles. Ceramics International 44, 12642-12647 (2018).

16 Miri, A., Darroudi, M. \& Sarani, M. Biosynthesis of cerium oxide nanoparticles and its cytotoxicity survey against colon cancer cell line. Applied Organometallic Chemistry 34, e5308 (2020).

17 Maqbool, Q. et al. Antimicrobial potential of green synthesized $\mathrm{CeO} 2$ nanoparticles from Olea europaea leaf extract. International journal of nanomedicine 11, 5015 (2016).

18 Loridant, S. Raman spectroscopy as a powerful tool to characterize ceria-based catalysts. Catalysis Today (2020).

19 Wiercigroch, E. et al. Raman and infrared spectroscopy of carbohydrates: A review. Spectrochimica Acta Part A: Molecular and Biomolecular Spectroscopy 185, 317-335 (2017).

20 Aseyd Nezhad, S., Es-haghi, A. \& Tabrizi, M. H. Green synthesis of cerium oxide nanoparticle using Origanum majorana L. leaf extract, its characterization and biological activities. Applied Organometallic Chemistry 34, e5314 (2020).

21 Khorrami, S., Zarrabi, A., Khaleghi, M., Danaei, M. \& Mozafari, M. Selective cytotoxicity of green synthesized silver nanoparticles against the MCF-7 tumor cell line and their enhanced antioxidant and antimicrobial properties. International journal of nanomedicine 13, 8013 (2018).

22 Park, E.-J., Choi, J., Park, Y.-K. \& Park, K. Oxidative stress induced by cerium oxide nanoparticles in cultured BEAS-2B cells. Toxicology 245, 90-100 (2008).

23 Demir, E. A review on nanotoxicity and nanogenotoxicity of different shapes of nanomaterials. Journal of Applied Toxicology 41, 118-147 (2021).

24 Ouiriemmi, I. et al. Towards sustainable removal of methylthioninium chloride by using adsorption-electroradical regeneration. Chemosphere 210, 476-485 (2018).

25 Kusmierek, E. A CeO2 Semiconductor as a Photocatalytic and Photoelectrocatalytic Material for the Remediation of Pollutants in Industrial Wastewater: A Review. Catalysts 10, 1435 (2020).

26 Zheng, X. et al. Synthesis of X-architecture $\mathrm{CeO} 2$ for the photodegradation of methylene blue under UV-light irradiation. Journal of Alloys and Compounds 705, 131-137 (2017).

27 Albukhaty, S., Al-Bayati, L., Al-Karagoly, H. \& Al-Musawi, S. Preparation and characterization of titanium dioxide nanoparticles and in vitro investigation of their cytotoxicity and antibacterial activity against Staphylococcus aureus and Escherichia coli. Animal Biotechnology, 1-7 (2020). 


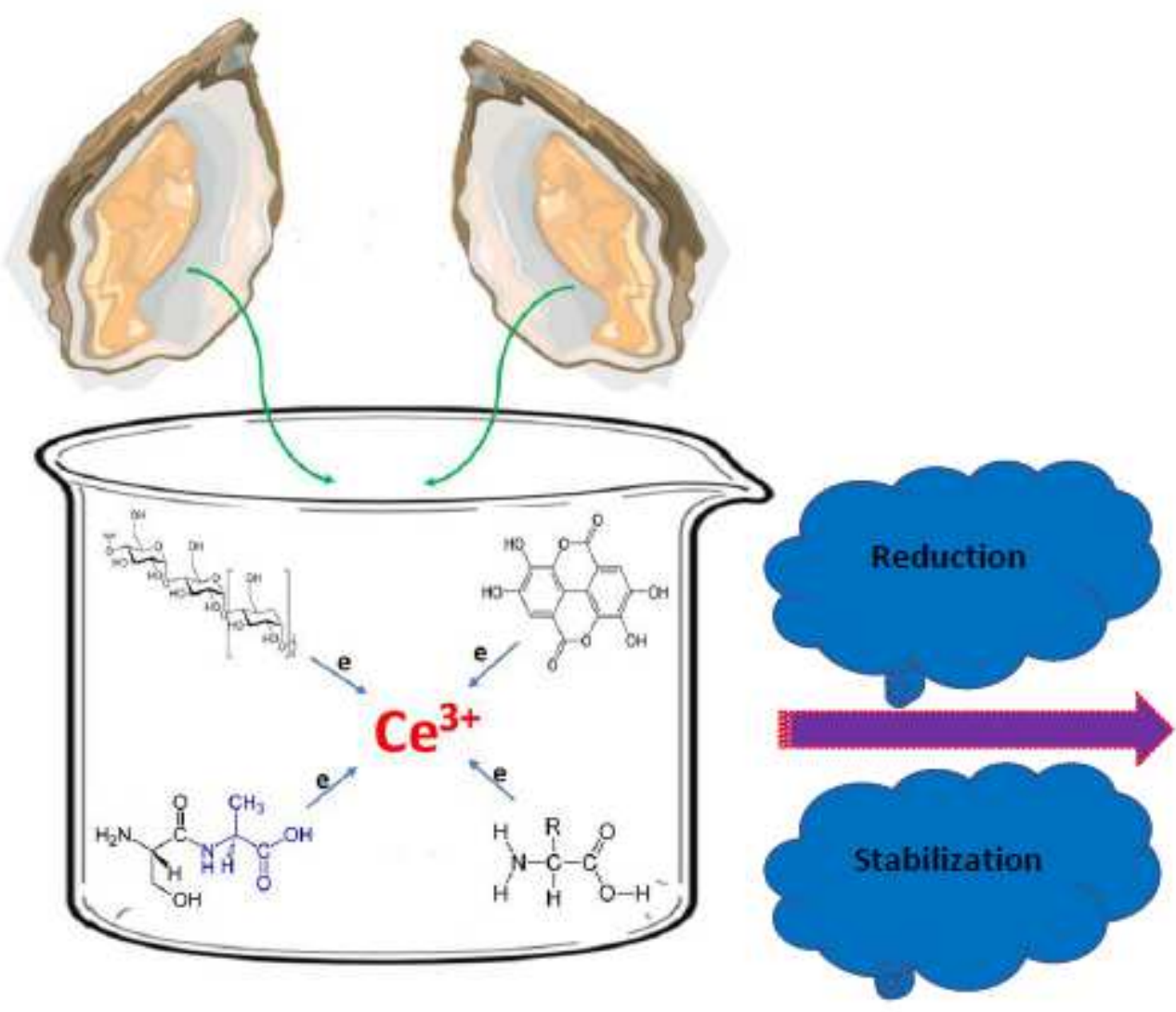

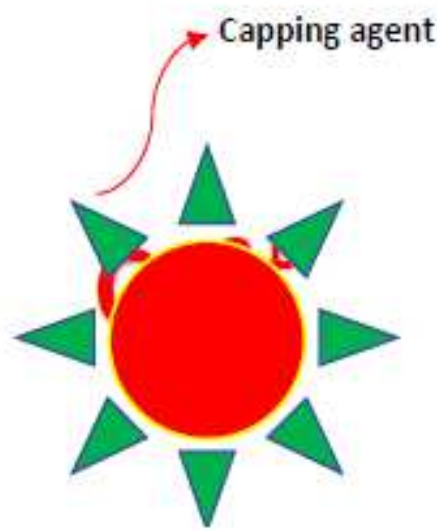

Nanoceria

\section{Figure 1}

Schematic representation of the biosynthetic pathway of nanoceria using marine oyster extract

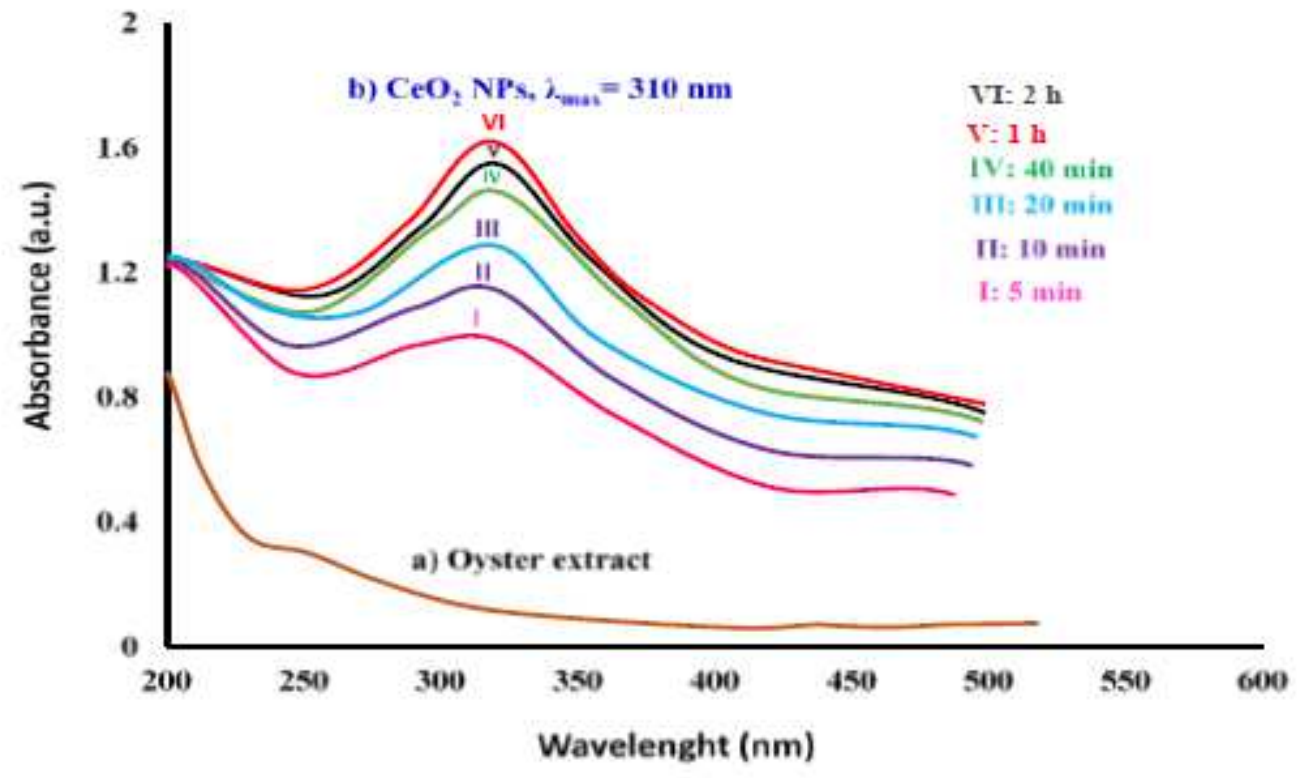

Figure 2 
UV-vis spectra of (a) raw oyster extract and (b) bioprepared CeO2 NPs as function of time

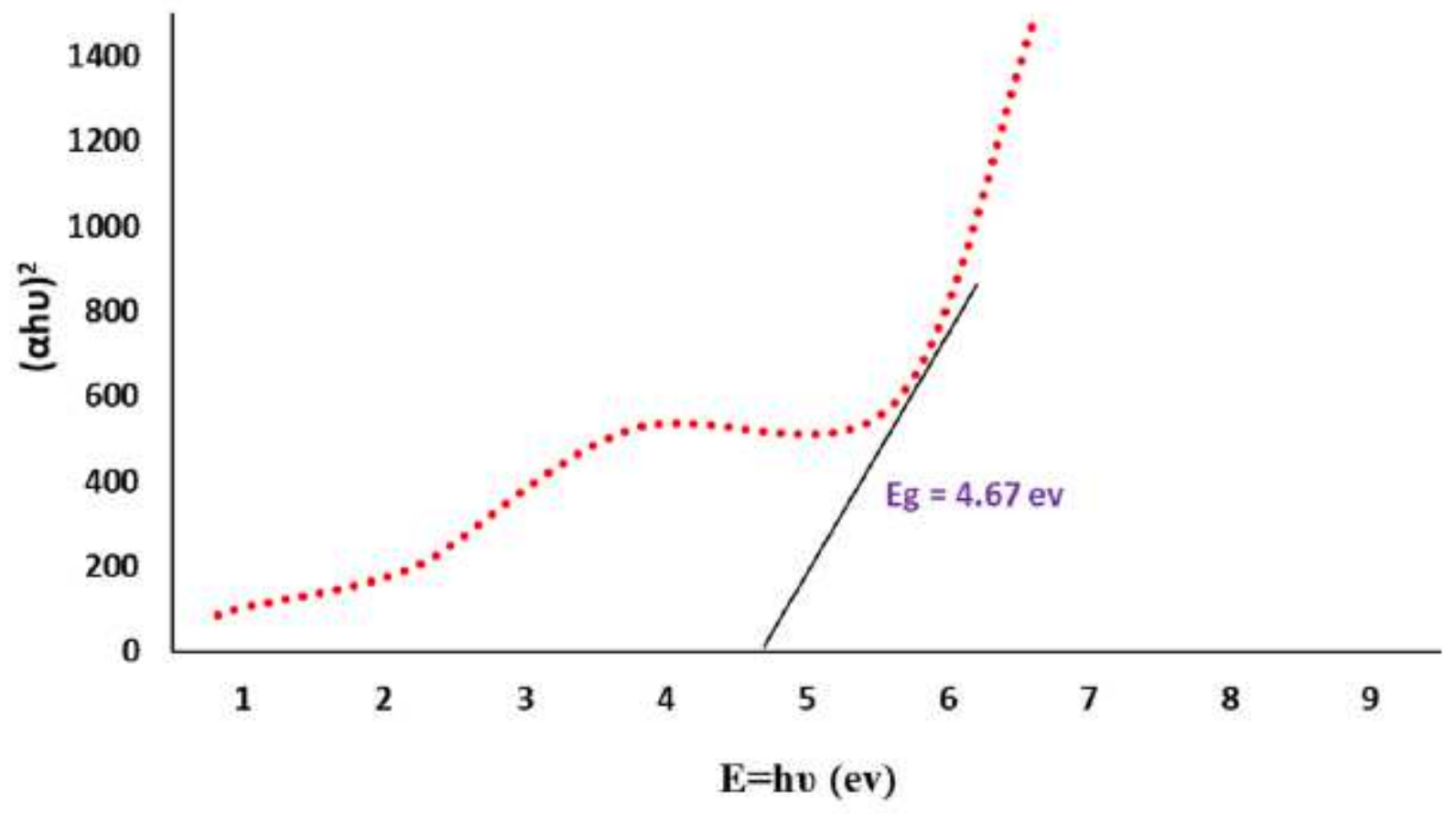

Figure 3

Tauc plot of biosynthesized CeO2 NPs using marine oyster extract

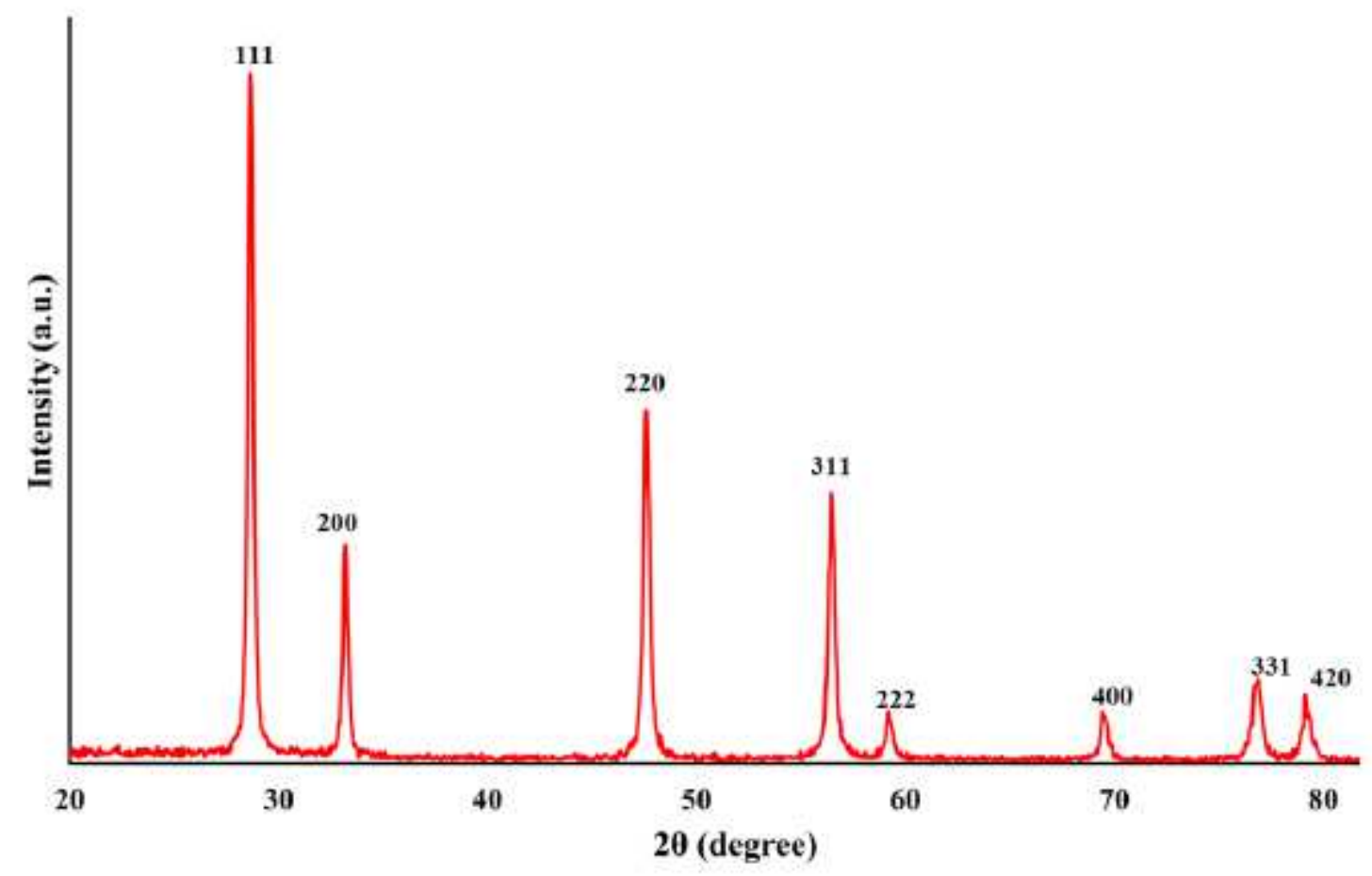

Figure 4 
XRD pattern of the marine Oyster assisted biosynthesized CeO 2 NPs.

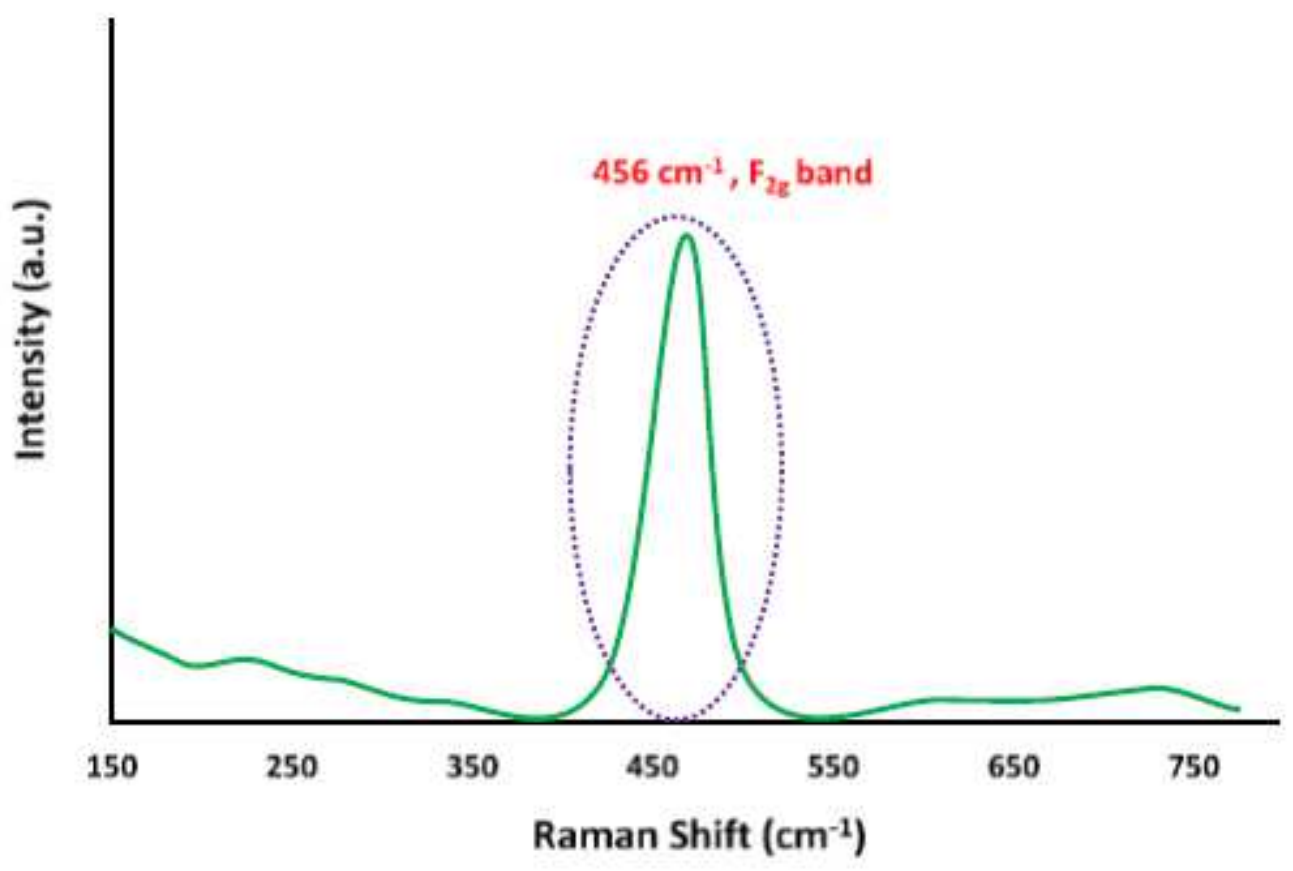

Figure 5

Raman spectrum of biofabricated $\mathrm{CeO} 2$ NPs using marine oyster extract

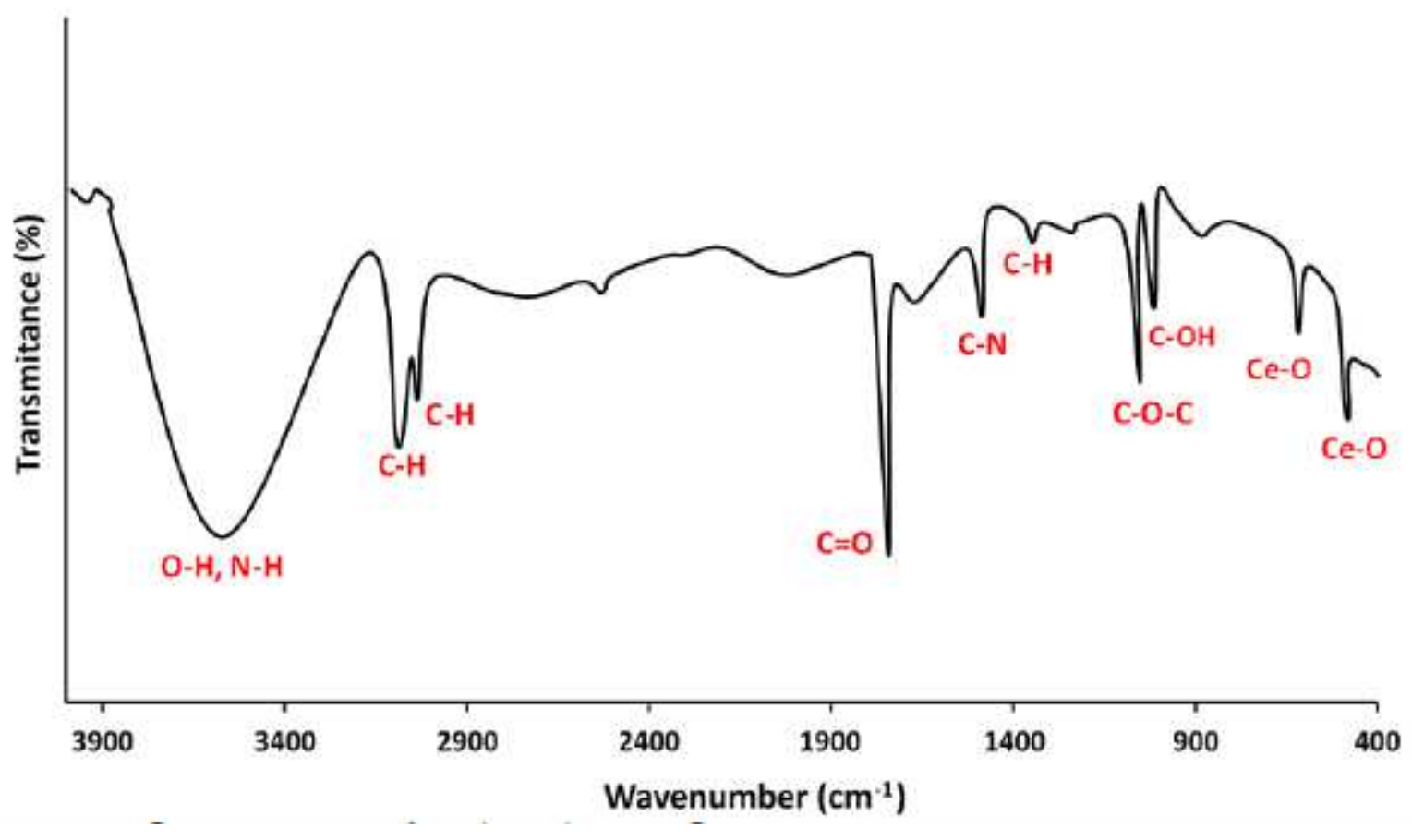

Figure 6

FTIR spectrum of the marine oyster assisted biosynthesized CeO 2 NPs. 


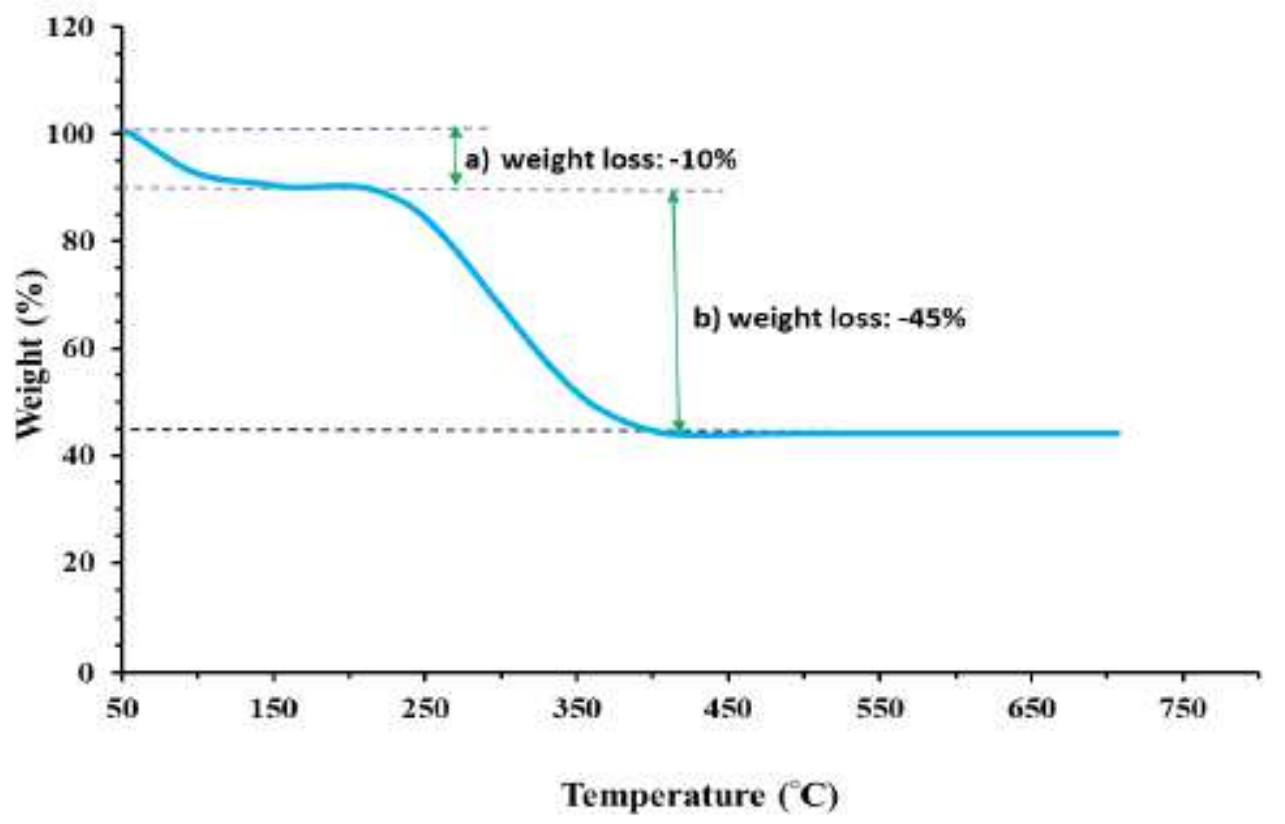

Figure 7

TGA plot of biofunctionalized CeO 2 NPs using marine oyster extract
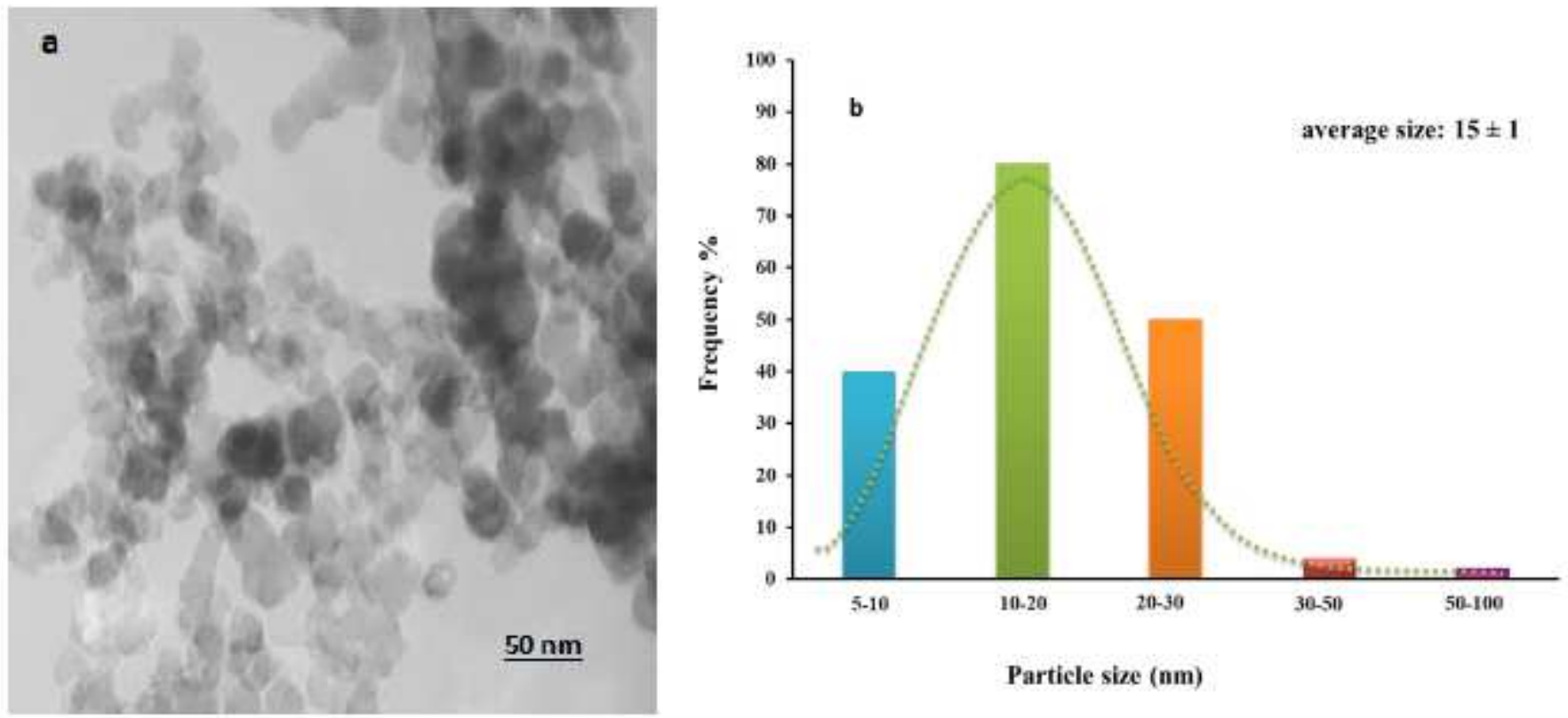

Figure 8

(a) TEM image and (b) particle size distribution histogram plot of the marine oyster assisted biosynthesized $\mathrm{CeO} 2 \mathrm{NPs}$. 


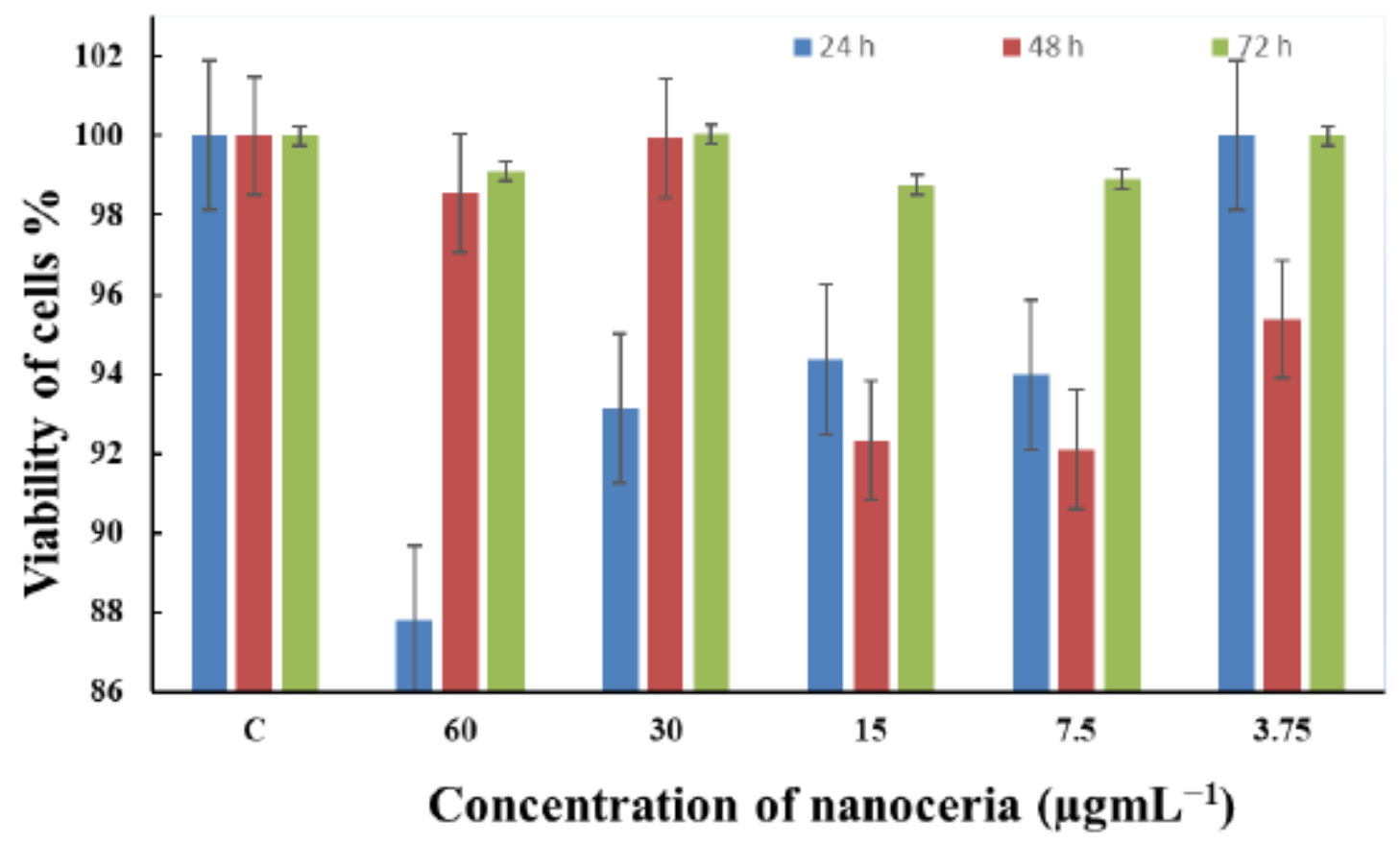

Figure 9

Cytotoxicity and biosafety of marine mediated nanoceria (CeO 2 NPs) against healthy L929 fibroblast cells 


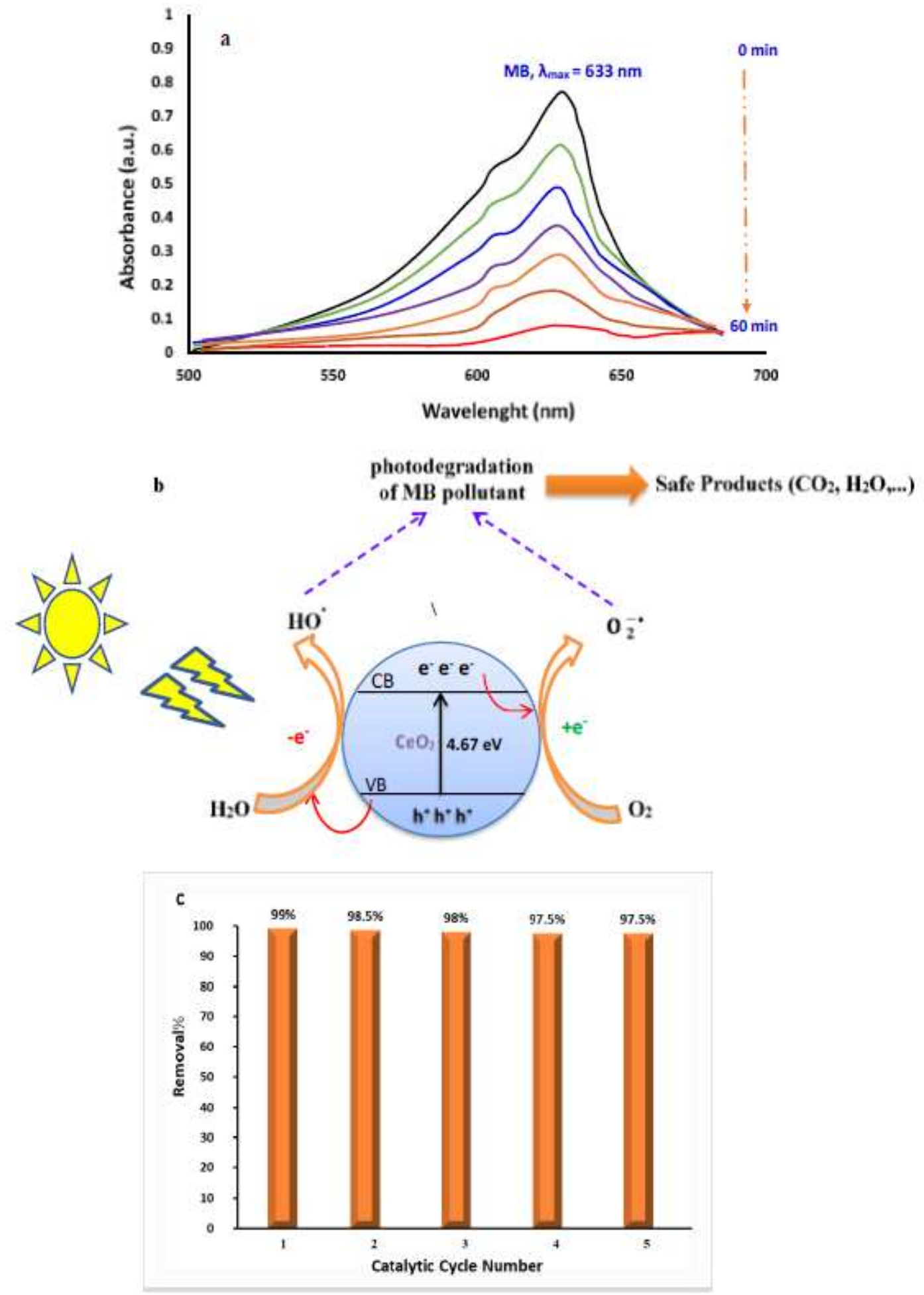

Figure 10

(a) Photocatalytic activity, (b) mechanism, and (c) recyclability of marine-mediated nanoceria against toward MB contaminant in aqueous solution 